\title{
Quantitative Near Infrared Spectroscopy Measurement of Cerebral Hemodynamics in Newborn Piglets
}

\author{
DEREK W. BROWN, PAUL A. PICOT, JAFAR GHARAVI NAEINI, ROGER SPRINGETT, \\ DAVID T. DELPY, AND TING-YIM LEE \\ Imaging Division, Lawson Health Research Institute, London, Ontario, Canada, N6A 4V2 [D.W.B., P.A.P., \\ J.G.N., T.-Y.L.]; Imaging Research Laboratories, Robarts Research Institute, London, Ontario, Canada, \\ N6A 5 K8 [D.W.B., T.-Y.L.]; Department of Medical Biophysics, University of Western Ontario, London, \\ Ontario, Canada, N6A 4B8 [D.W.B., P.A.P., J.G.N., T.-Y.L.]; Department of Medical Physics and \\ Bioengineering, University College London, London, U.K., WC1E 6JA [R.S., D.T.D.]
}

\section{ABSTRACT}

Severely premature infants are often at increased risk of cerebral hemorrhage and/or ischemic injury caused by immature autoregulatory control of blood flow to the brain. If blood flow is too high, the infant is at risk of hemorrhage, whereas too little blood flow can result in ischemic injury. The development of a noninvasive, bedside means of measuring cerebral hemodynamics would greatly facilitate both diagnosis and monitoring of afflicted individuals. It is to this end that we have developed a near infrared spectroscopy (NIRS) system that allows for quantitative, bedside measurement of cerebral blood flow (CBF), cerebral blood volume (CBV), and mean transit time (MTT). The technique requires an i.v. injection of the near infrared chromophore indocyanine green. Six newborn piglets, median age of $18 \mathrm{~h}$ (range 6-54 h), median weight of $1.75 \mathrm{~kg}$ (range 1.5-2.1 $\mathrm{kg}$ ), were studied. Measurements of CBF, CBV, and MTT were made at normocapnia, hypocapnia, and hypercapnia to test the technique over a range of hemodynamic conditions. The accuracy of our new approach has been determined by direct com- parison with measurements made using a previously validated computed tomography technique. Paired $t$ tests showed no significant difference between computed tomography and NIRS measurements of CBF, CBV, and MTT, and mean biases between the two methods were $-2.05 \mathrm{~mL} \cdot \mathrm{min}^{-1} \cdot 100 \mathrm{~g}^{-1},-0.18$ $\mathrm{mL} \cdot 100 \mathrm{~g}^{-1}$, and $0.43 \mathrm{~s}$, respectively. The precision of NIRS $\mathrm{CBF}, \mathrm{CBV}$, and MTT measurements, as determined by repeatedmeasures ANOVA, was $9.71 \%, 13.05 \%$, and $7.57 \%$, respectively. (Pediatr Res 51: 564-570, 2002)

CBF, cerebral blood flow

\section{Abbreviations:}

CBV, cerebral blood volume

MTT, mean transit time

CT, computed tomography

NIRS, near infrared spectroscopy

ICG, indocyanine green

$\mathbf{P a C O}_{2}$, partial arterial $\mathrm{CO}_{2}$ tension
Since the first publication by Jobsis in 1977 (1), NIRS has been used in a variety of studies to investigate cerebral hemodynamics $(2,3)$. The underlying principles behind the use of NIRS to probe biologic media are relatively simple and have been described in detail elsewhere $(1,4-8)$. There exist in biologic tissue four endogenous near infrared (NIR) light absorbers-oxy-Hb $\left(\mathrm{HbO}_{2}\right)$, deoxy- $\mathrm{Hb}(\mathrm{Hb})$, cytochrome oxidase $(\mathrm{Cyt})$, and water. Because $\mathrm{HbO}_{2}$ and $\mathrm{Hb}$ are generally present at relatively low concentrations in tissue, NIR light is able to penetrate tissue to a greater extent than other low-energy forms of light, in some cases up to distances of $8-9 \mathrm{~cm}(6)$.

Received February 8, 2001; accepted August 8, 2001

Correspondence: Ting-Yim Lee, Ph.D., Imaging Division, Lawson Health Research Institute, 268 Grosvenor Street, London, Ontario, Canada, N6A 4V2; e-mail: tlee@irus.rri.on.ca

Supported by Photonics Research Ontario, the Lawson Health Research Institute, Robarts Research Institute, and the Child Health Research Institute.
As NIR light enters tissue, it is multiply scattered. The result of this scatter is that the total path length traveled by the NIR light is greater than the physical distance between the points of emission and detection. This extra distance can be accounted for using the differential path length factor (DPF), first described by Delpy et al. (9). With accurate knowledge of the DPF, a modified version of the Beer-Lambert law can be used to determine absolute changes in concentrations of NIR absorbers within tissue:

$$
\Delta \mathrm{c}=\frac{\Delta \mathrm{A}}{\alpha \cdot \mathrm{L} \cdot \mathrm{B}}
$$

where $\Delta \mathrm{c}$ is the change in concentration, $\Delta \mathrm{A}$ is the change in attenuation, $\alpha$ is the extinction coefficient, $\mathrm{L}$ is the physical distance between emission and detection of NIR light, and B is the DPF. Measurement of concentration changes over time can 
then be used to quantify cerebral hemodynamics, namely CBF $(10,11)$.

Previous attempts to investigate cerebral hemodynamics using NIRS have achieved somewhat limited success. This has been, in part, due to the use of discrete wavelength spectrometers that acquire intensity measurements at several distinct wavelengths. $\mathrm{CBF}, \mathrm{CBV}$, and MTT calculations made using these spectrometers are subject to error resulting from an inability to accurately measure the individual DPF. Also, previous algorithms used to calculate $\mathrm{CBF}, \mathrm{CBV}$, and MTT have been unable to account for loss of tracer from the brain resulting from venous outflow, greatly limiting the length of relevant data acquisition that can be used in the calculation of CBF (10). We used a cooled CCD (charged coupled device) spectrometer to acquire high signal-to-noise NIR spectra from 600 to $980 \mathrm{~nm}$ with a spectral sampling width of $0.395 \pm 0.001$ $\mathrm{nm}$. This spectrometer enables the individual DPF to be estimated accurately using the second derivative technique, described by Matcher et al. (12). In addition, outflow of tracer from the brain was explicitly considered in our $\mathrm{CBF}, \mathrm{CBV}$, and MTT calculations, thus removing another confounder of the accuracy of the measurement.

In this study, we have measured CBF, CBV, and MTT in six newborn piglets using a cooled CCD NIRS system. The accuracy of our new approach has been determined by direct comparison with measurements made using a previously validated CT technique (13). To test the accuracy of our new approach over a range of hemodynamic conditions, measurements were made at various $\mathrm{PaCO}_{2}$ levels: hypocapnia $\left(\mathrm{PaCO}_{2}\right.$ $30 \pm 4 \mathrm{~mm} \mathrm{Hg})$, normocapnia $\left(\mathrm{PacO}_{2} 40 \pm 4 \mathrm{~mm} \mathrm{Hg}\right.$ ), and hypercapnia $\left(\mathrm{PaCO}_{2} 50 \pm 4 \mathrm{~mm} \mathrm{Hg}\right)$.

$\mathrm{PaCO}_{2}$ is now generally considered to be the most influential regulator of the cerebral circulation (14), and, although the exact mechanism of the response is not known, the physiologic basis for it is well understood. $\mathrm{CO}_{2}$ is one of the major products of cellular metabolism. Thus, an increase in $\mathrm{CO}_{2}$ levels indicates an increase in cerebral cellular activity. This increased metabolism demands increased oxygen delivery, which is achieved through increased $\mathrm{CBF}$ and $\mathrm{CBV}$ and decreased MTT. Higher $\mathrm{CO}_{2}$ levels would give rise to both increased $\mathrm{CBF}$ and $\mathrm{CBV}$ and decreased MTT. Similarly, lower $\mathrm{CO}_{2}$ levels would give rise to decreased $\mathrm{CBF}$ and $\mathrm{CBV}$ and increased MTT. Cerebral $\mathrm{CO}_{2}$ reactivity is defined as the change in $\mathrm{CBF}$ per unit change in $\mathrm{PaCO}_{2}$ and has been shown to be linear in normal individuals for $\mathrm{PaCO}_{2}$ values ranging from 25 to $65 \mathrm{~mm} \mathrm{Hg}(15)$.

Crucial to the comparison of NIRS with CT measurements is the mapping of the region through which detected NIR light has traveled. Without this detailed knowledge, a comparison between NIRS and CT is not possible. Previous studies, using computer modeling, have shown that photon paths through the brain can be traced and used to determine the most likely NIR light path (16). Thus, the volume for CBF, CBV, and MTT measurements by CT and NIRS can be matched, eliminating any potential sampling errors. These studies show that, in a homogeneous medium, the detected NIR light travels in a banana-shaped path through the head. The maximum penetration depth of the path is given approximately by the square root of the physical distance between the points of emission and detection.

Theory. The CBF, CBV, and MTT calculations are based on a generalized application of the Fick principle, which states

$$
Q(t)=F \int_{0}^{t}\left[C_{a}(u)-C_{v}(u)\right] d u
$$

where $\mathrm{Q}(\mathrm{t}), \mathrm{C}_{\mathrm{a}}(\mathrm{t})$, and $\mathrm{C}_{\mathrm{v}}(\mathrm{t})$ are the tissue, arterial, and venous concentrations of the NIR chromophore, respectively, and F is the cerebral blood flow. Previous studies have made use of the assumption that there is no venous outflow of the chromophore during the time interval 0 to $t$, in which case equation 2 can be simplified to

$$
Q(t)=F \int_{0}^{t} C_{a}(u) d u
$$

Blood flow can thus be estimated at each time within the time interval ( 0 to $t$ ) by calculating the slope of the tissue concentration curve versus the integral of the arterial concentration curve (11). Although useful, this technique carries with it a serious drawback. To assume no venous outflow, measurements must be made within the minimum transit time of the organ, typically only 3-5 $\mathrm{s}$ in the brain. This limitation in the amount of usable data results in variability in the blood flow estimation.

We have developed an alternative means of measuring CBF in which the outflow of the tracer from the brain is explicitly considered in the calculation. If we consider a network of capillaries in a certain mass of brain tissue, then CBF into the network is $\mathrm{F}\left(\mathrm{mL} \cdot \mathrm{min}^{-1} \cdot 100 \mathrm{~g}^{-1}\right)$ and is carrying with it ICG at a concentration of $\mathrm{C}_{\mathrm{a}}(\mathrm{t})\left(\mu \mathrm{mol} \cdot \mathrm{mL}^{-1}\right)$. The tissue concentration function, or the tissue residue function, $\mathrm{Q}(\mathrm{t})$ $\left(\mu \mathrm{mol} \cdot \mathrm{mL}^{-1}\right)$, can be measured using NIRS. In the special case when $F \cdot C_{a}$ is a delta function such that a unit mass of ICG is deposited in the tissue instantaneously at time 0 , then the tissue residue function becomes the impulse residue function (IRF) or $\mathrm{R}(\mathrm{t})$ (17). For a tracer that remains intravascular, such as ICG, the IRF is of the general form shown in Figure 1. The length of the initial plateau at unity height corresponds to the minimum time required for the blood to traverse the network from the arterial inlet to the venous outlet, or the minimum transit time.

When ICG is injected intravenously in a peripheral vein, the rate of delivery of the tracer to the capillary network is $F \cdot C_{a}(t)$. If the mass of ICG in the network is linear with respect to the arterial (input) concentration and $\mathrm{F}$ is constant in time, then, by linear superimposition, it can be shown that

$$
\mathrm{Q}(\mathrm{t})=\mathrm{F} \cdot \mathrm{C}_{\mathrm{a}}(\mathrm{t}) * \mathrm{R}(\mathrm{t})
$$

where * is the convolution operator. $\mathrm{Q}(\mathrm{t})$ and $\mathrm{C}_{\mathrm{a}}(\mathrm{t})$ can be measured and deconvolution between the two curves then yields $F \cdot R(t)(13)$, the initial height of which corresponds to CBF and the 


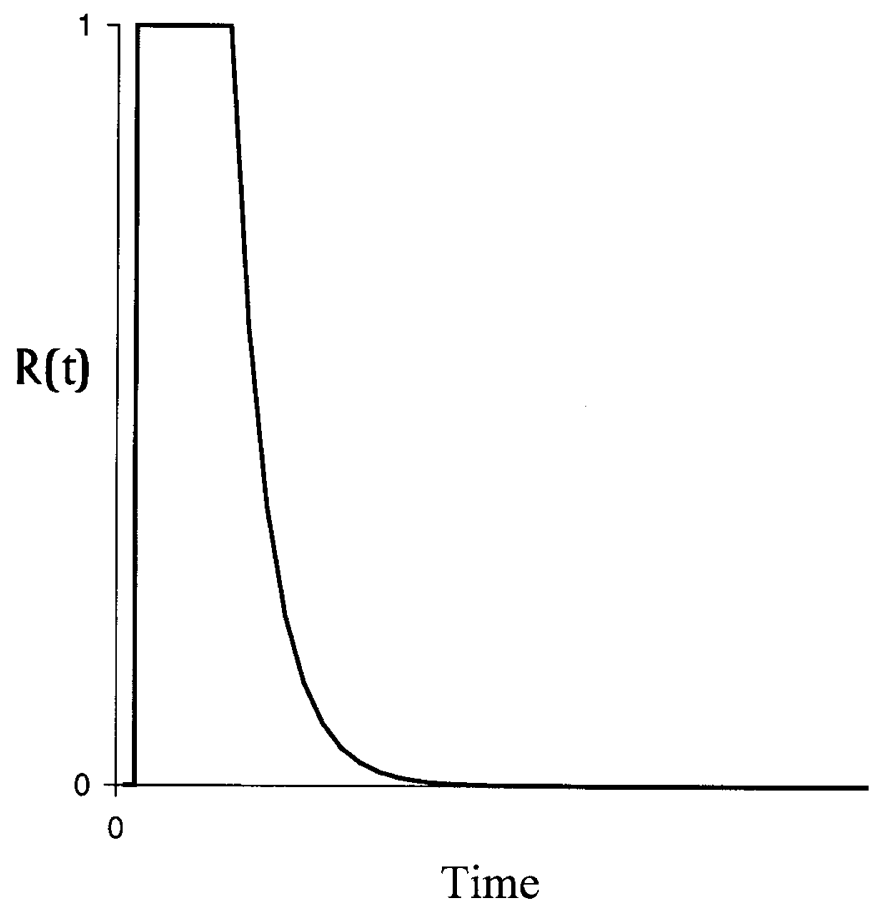

Figure 1. Schematic representation of the IRF for a vascular network in which the blood flow tracer (ICG) remains intravascular.

area under the curve to CBV (18). From the central volume principle (19), MTT can then be calculated as follows:

$$
\mathrm{MTT}=\frac{\mathrm{CBV}}{\mathrm{CBF}}
$$

\section{METHODS}

Subjects and studies. Six newborn piglets, median age $18 \mathrm{~h}$ (range 6-54 h) and median weight $1.75 \mathrm{~kg}$ (range 1.5-2.1 $\mathrm{kg}$ ), were studied. The study was approved by the Council on Animal Care-Animal Use Subcommittee at the University of Western Ontario. The piglets were anesthetized using $1 \%$ isoflurane with vecuronium, intubated, and ventilated. Physiologic parameters, including partial arterial oxygen tension $\left(\mathrm{PaO}_{2}\right)$, bicarbonate levels $\left(\mathrm{HCO}_{3}\right), \mathrm{pH}$, and mean arterial blood pressure were monitored throughout the experiment.

The piglets were placed in a Lightspeed QXi multislice CT scanner (General Electric Medical Systems, Milwaukee, WI, U.S.A.). Because of the portable nature of the NIRS system, both NIRS and CT measurements could be made with the piglet in the
CT scanner. Table 1 shows the number of CT and NIRS measurements made at each $\mathrm{PaCO}_{2}$ level for individual piglets. In some piglets, we were able to perform CT and NIRS measurements only once at each $\mathrm{PacO}_{2}$ level because of time constraints or technical problems in maintaining the piglet at stable conditions. In other piglets, we were able to perform two NIRS measurements for each CT measurement. CT and NIRS measurements were performed at only two $\mathrm{PaCO}_{2}$ levels in two of the six piglets and at all three $\mathrm{PaCO}_{2}$ levels in the remaining four piglets. The comparison of NIRS and CT data were analyzed by two-way ANOVA with unequal repeated measures (20).

NIRS tissue ICG concentration measurement. The NIRS system is comprised of a tungsten halogen lightsource, two fiberoptic cables, and a spectrometer. The spectrometer consists of a holographic grating housed in a custom-designed, light-tight container and a cooled CCD camera (Wright Instruments, Enfield, Middlesex, U.K.). For the NIRS measurements, two fiberoptic optodes were placed $3.0 \mathrm{~cm}$ apart on the head of the piglet. One of the optodes was used to transmit and the other to collect NIR light in the range of $600-980 \mathrm{~nm}$. Multiply scattered light collected from the head of the piglet was channelled to the holographic grating, where it was dispersed across the cooled CCD chip (cooled to $-70^{\circ} \mathrm{C}$ to reduce electronic dark noise). The piglets received a $1.0-\mathrm{mL}$ injection of ICG solution at a concentration of $0.1 \mathrm{mg} / \mathrm{mL}$ into the ear vein. A modified version of the Beer-Lambert law, which uses the DPF to account for the scatter, was used to calculate absolute change in ICG concentration within the illuminated tissue region with a temporal resolution of $200 \mathrm{~ms}$. Because the concentration of ICG in tissue is 0 before injection, the absolute change in ICG is therefore the absolute concentration of ICG in tissue.

Arterial ICG concentration measurement. Arterial ICG concentration was measured noninvasively on a hindfoot of the piglet using a dye densitogram unit (model DDG-2001 A/K, Nihon Kohden, Tokyo, Japan). The dye densitogram probe was held on the skin of the piglet using a springloaded clip, much the same as is used for a regular pulse oximeter probe. This system measured absolute ICG concentration in the arteries of the piglet, making one measurement with every heartbeat. The normal piglet heart rate is between 110 and 130 beats/min, giving approximately one measurement every half second.

CT measurement. For CT measurements, each piglet received a $1.0 \mathrm{~mL} / \mathrm{kg}$ injection of Omnipaque 300 (Nycomed Imaging AS, Oslo, Norway), a nonionic, radio-opaque iodine solution, at a rate of $1.0 \mathrm{~mL} / \mathrm{s}$ into the umbilical vein. CT

Table 1. Number of CT and NIRS measurements at each $\mathrm{PaCO}_{2}$ level

\begin{tabular}{|c|c|c|c|c|c|c|}
\hline \multirow{2}{*}{$\begin{array}{c}\text { Piglet } \\
\text { no. }\end{array}$} & \multicolumn{3}{|c|}{$\mathrm{CT}$} & \multicolumn{3}{|c|}{ NIRS } \\
\hline & Hypocapnia & Normocapnia & Hypercapnia & Hypocapnia & Normocapnia & Hypercapnia \\
\hline 1 & 1 & 1 & $\mathrm{X}$ & 2 & 1 & $\mathrm{X}$ \\
\hline 3 & 1 & 1 & 1 & 2 & 2 & 1 \\
\hline 4 & 2 & 1 & $\mathrm{X}$ & 2 & 2 & $\mathrm{X}$ \\
\hline 5 & 1 & 1 & 1 & 1 & 2 & 2 \\
\hline
\end{tabular}

$\mathrm{X}=$ no measurement was made. 


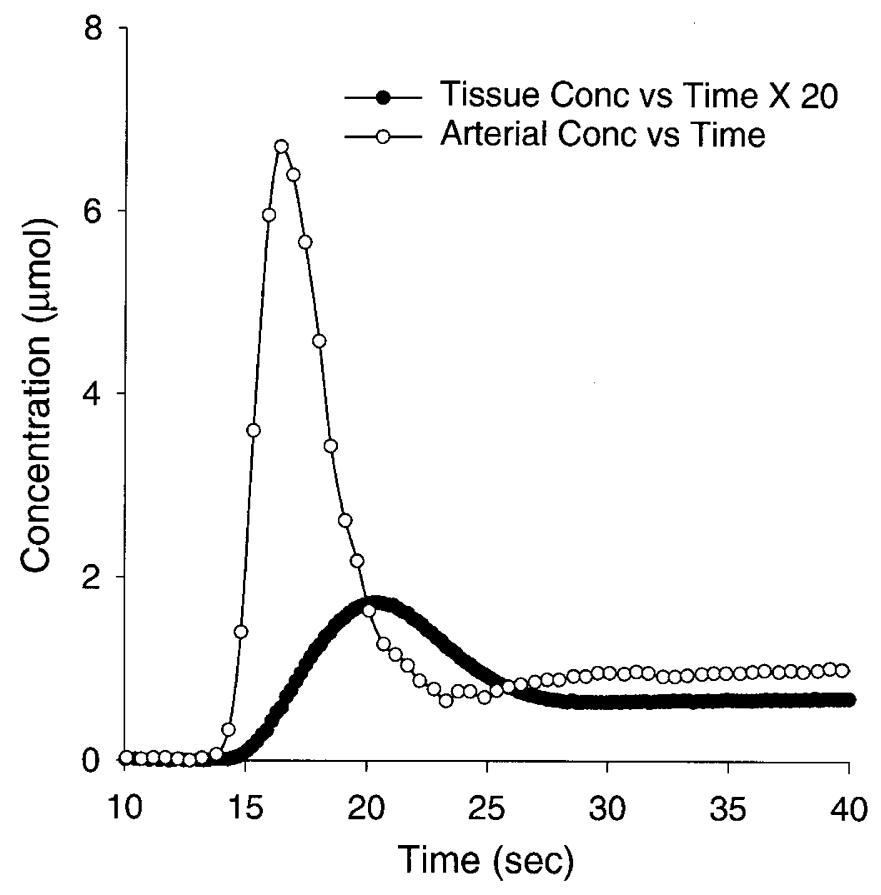

Figure 2. Representative tissue and arterial ICG concentration curves measured with NIRS and the dye densitogram unit, respectively. Curves are measured simultaneously over a period of $40 \mathrm{~s}$ after injection of $1.0 \mathrm{~mL}$ of ICG solution at a concentration of $0.1 \mathrm{mg} / \mathrm{mL}$. The peak arterial concentration is approximately 20 times greater than that of tissue. This is because blood volume in tissue is approximately $5 \%$ of the total tissue volume.

scans were then performed with a Lightspeed QXi multislice scanner. Each scan provided four simultaneously obtained slices, once every second, for a period of $40 \mathrm{~s}$. The four slices were spaced $5.0 \mathrm{~mm}$ apart, coronally on the head of the piglet, with a field of view $(12 \mathrm{~cm})$ set to encompass the entire head and front legs of the piglet, in a prone position. From this series of images, it was possible to determine both arterial and tissue concentrations of the contrast agent with a temporal resolution of $1.0 \mathrm{~s}$ (13). Functional maps of CBF, $\mathrm{CBV}$, and MTT across the four slices of the piglet head were calculated using the CT perfusion software package from General Electric Medical Systems, which was developed and validated in our lab (13).

Deconvolution algorithm. For the NIRS studies, the measured $\mathrm{Q}(\mathrm{t})$ and $\mathrm{C}_{\mathrm{a}}(\mathrm{t})$ were deconvolved, according to equation 4 , to yield the blood flow scaled IRF, or FR(t). In the implementation of the deconvolution algorithm, equation 4 was first discretized, resulting in a system of linear equations. Because negative values for $\mathrm{R}(\mathrm{t})$ are not allowed, the system of equations was solved by the non-negative least squares algorithm of Lawson and Hanson (21).

Accuracy and precision. The accuracy of hemodynamic measurements made using the NIRS system was determined via direct comparison with CT results. Because the NIRS system is portable, both sets of measurements were made with the animal in the CT scanner. This allowed for direct comparison of hemodynamic measurements obtained by the two modalities at various $\mathrm{PaCO}_{2}$ levels. The NIRS measurements are averaged values over the entire detected NIR light path. To compare NIRS with CT measurements, averages in the CT functional images over the area corresponding to the detected NIR light path were calculated.

\section{RESULTS}

The NIRS system employs an emission/detection scheme consisting of two optodes placed $3 \mathrm{~cm}$ apart on the head of the piglet. Calculations of $\mathrm{CBF}, \mathrm{CBV}$, and MTT are averages over the entire tissue region illuminated by the detected NIR light. Tissue and arterial concentration versus time graphs, as measured with the NIRS and dye densitogram unit systems, are presented in Figure 2. The peak arterial concentration is approximately 20 times greater than that of tissue. This is because blood volume in tissue is approximately 5\% of total tissue volume. The result of deconvolution between these two curves, the blood flow scaled IRF, is presented in Figure 3, and a graph of the NIRS-measured $\mathrm{CBF} \mathrm{PaCO}_{2}$ reactivity is presented in Figure 4. Linear regression was used to fit a line to the $\mathrm{CBF}$ $\mathrm{PaCO}_{2}$ reactivity data set as a whole. This line is shown in Figure 4 as a dashed line. The slope of the regression line is $1.36 \mathrm{~mL} \cdot \mathrm{min}^{-1} \cdot 100 \mathrm{~g}^{-1} / \mathrm{mm} \mathrm{Hg}$. Thus, for every $\mathrm{mm} \mathrm{Hg}$ increase in $\mathrm{PaCO}_{2}, \mathrm{CBF}$ increases by $1.36 \mathrm{~mL} \cdot \mathrm{min}^{-1} \cdot 100 \mathrm{~g}^{-1}$. Similar graphs have been produced for CBV and MTT but are omitted here in the interest of space.

Table 2 presents the measured physiologic parameters for repeated NIRS measurements at various $\mathrm{PaCO}_{2}$ levels on each piglet. Paired $t$ tests showed no significant difference between physiologic parameters for repeated measurements $(p>0.05)$.

Figure $5 A$ shows two of a set of four cross-sectional CT images at peak contrast enhancement. The brain of the piglet was centered in the field of view of the CT scanner. The two front legs of the

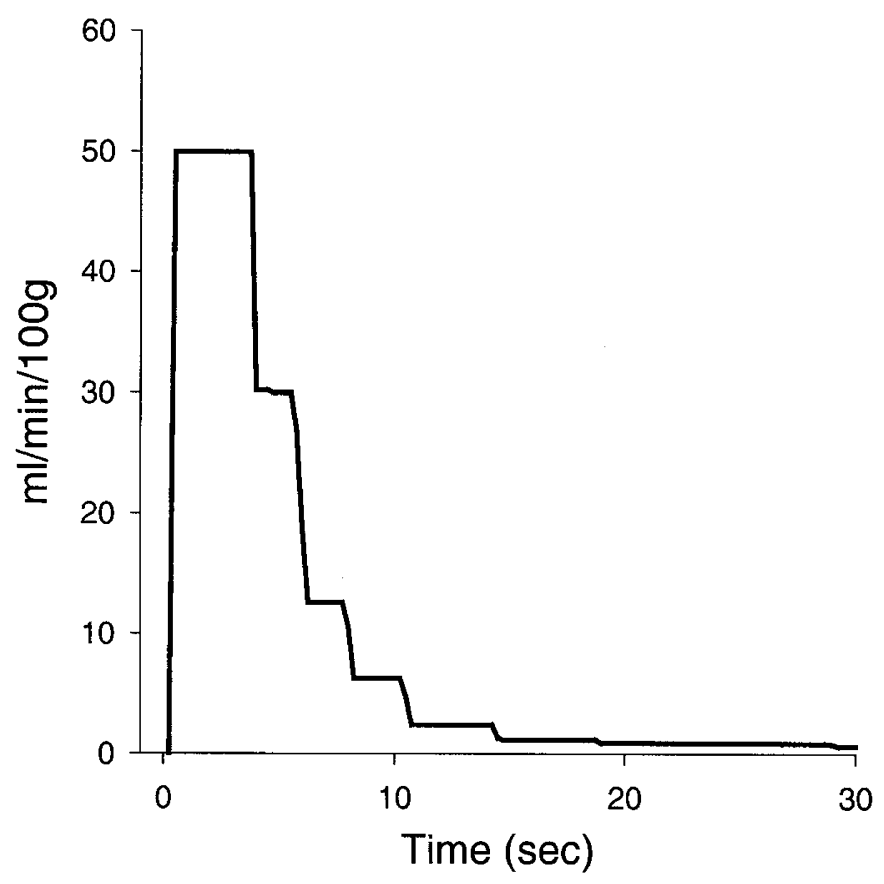

Figure 3. Calculated impulse residue function. CBF scaled impulse residue function $[F \cdot R(t)]$ from a piglet at normocapnia. Height of initial plateau yields $\mathrm{CBF}$, area under the curve yields $\mathrm{CBV}$, and MTT is equal to the area (CBV) divided by the height (CBF). 


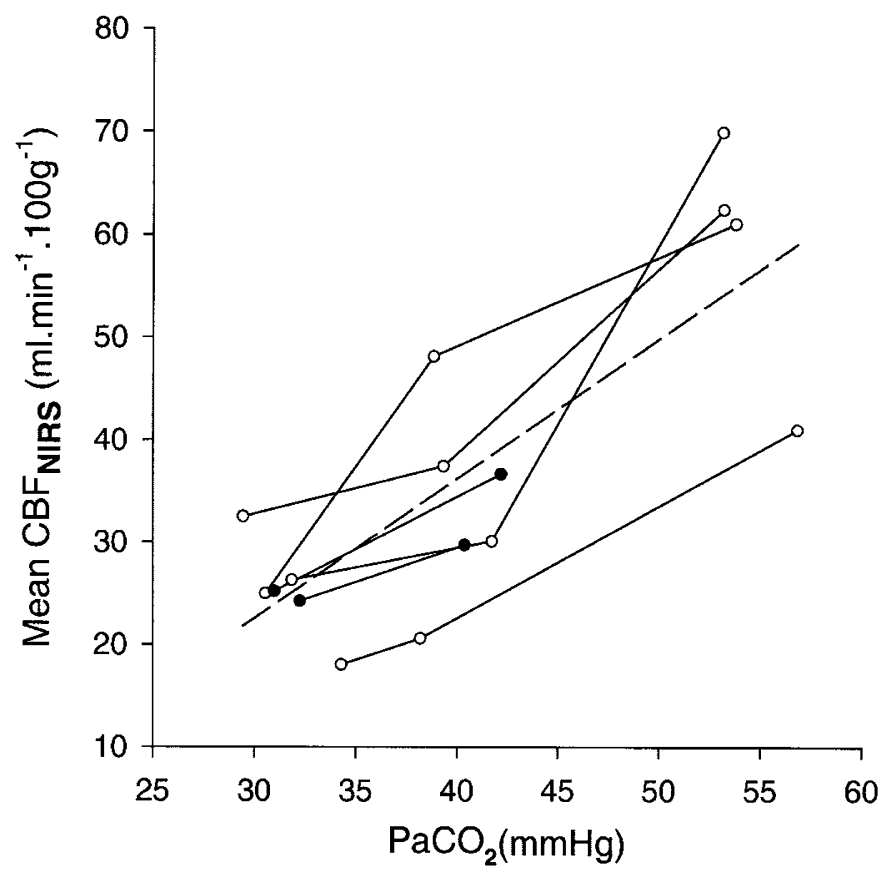

Figure 4. NIRS-measured $\mathrm{PaCO}_{2}$ reactivity. Mean cerebral blood flow at various $\mathrm{PaCO}_{2}$ levels for six piglets. In four piglets, repeat CBF measurements were made at each of three $\mathrm{PaCO}_{2}$ levels, and means at each level are presented (open circles). In the remaining two piglets, repeat CBF measurements were made at two $\mathrm{PacO}_{2}$ levels and means at each level are presented (filled circles). The dashed line shows the linear regression line for the $\mathrm{CBF} \mathrm{PaCO}_{2}$ reactivity data set as a whole. The slope of the regression line is $1.36 \mathrm{~mL} \cdot \mathrm{min}^{-1} \cdot 100 \mathrm{~g}^{-1} / \mathrm{mm} \mathrm{Hg}$.

piglet are visible in the bottom corners of the image. The piglet was held in a frame, visible above and to the side of the animal. Two holes used to hold the NIR probes on the head of the piglet are visible in the top section of the frame. Figure 5, $B-D$, shows $\mathrm{CBF}, \mathrm{CBV}$, and MTT cross-sectional maps, at normocapnia, corresponding to the images presented in Figure $5 A$.

Figure 6 presents the Bland-Altman plot comparing $\mathrm{CT}$ and NIRS measurements of CBF (22). The mean difference between the two methods is $-2.05 \mathrm{~mL} \cdot \mathrm{min}^{-1} \cdot 100 \mathrm{~g}^{-1}$. The limits of agreement, the region in which $95 \%$ of the differences lie, are -14.48 and $10.39 \mathrm{~mL} \cdot \mathrm{min}^{-1} \cdot 100 \mathrm{~g}^{-1}$. The $95 \%$ confidence interval of the mean difference, the region in which we expect (with $95 \%$ confidence) the bias lies, is -4.21 to 0.12 $\mathrm{mL} \cdot \mathrm{min}^{-1} \cdot 100 \mathrm{~g}^{-1}$. Similar Bland-Altman plots for CBV and MTT measurements have also been produced and show mean differences of $-0.18 \mathrm{~mL} \cdot 100 \mathrm{~g}^{-1}$ and $0.43 \mathrm{~s}$, respectively. Two-way ANOVA showed no significant differences between $\mathrm{CBF}, \mathrm{CBV}$, and MTT measurements made using the CT and NIRS techniques $(p>0.1)$. Regression plots showed relationships of $\mathrm{CBF}_{\mathrm{CT}}=-1.98+1.00 \cdot \mathrm{CBF}_{\mathrm{NIRS}}\left(r^{2}=0.86\right)$ for $\mathrm{CBF}, \mathrm{CBV}_{\mathrm{CT}}=0.29+0.84 \cdot \mathrm{CBV}_{\mathrm{NIRS}}\left(r^{2}=0.75\right)$ for $\mathrm{CBV}$, and $\mathrm{MTT}_{\mathrm{CT}}=0.11+1.07 \cdot \mathrm{MTT}_{\mathrm{NIRS}}\left(r^{2}=0.80\right)$ for MTT. The precision of NIRS CBF, CBV, and MTT measurements, determined using repeated-measures ANOVA, are 9.71\%, $13.05 \%$, and $7.57 \%$, respectively.
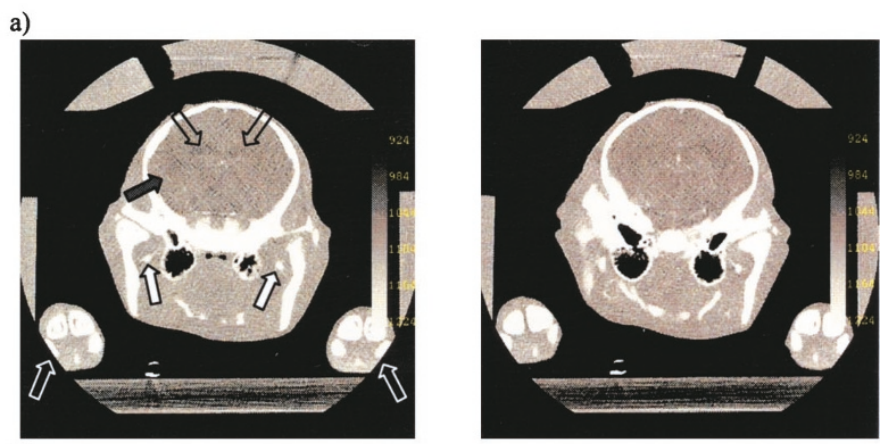

b)
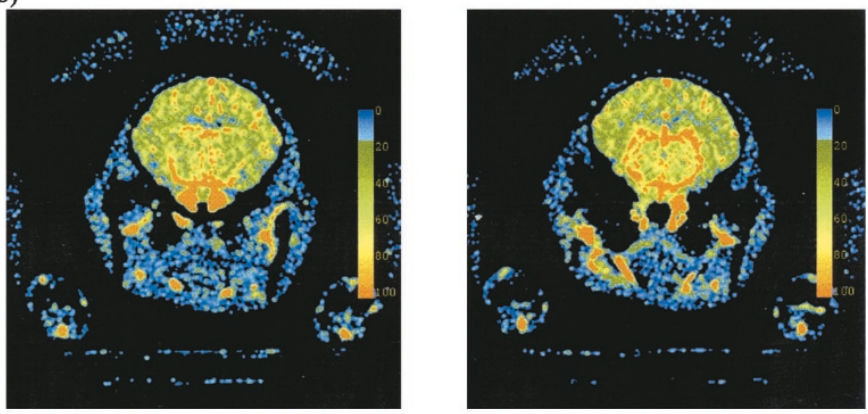

c)
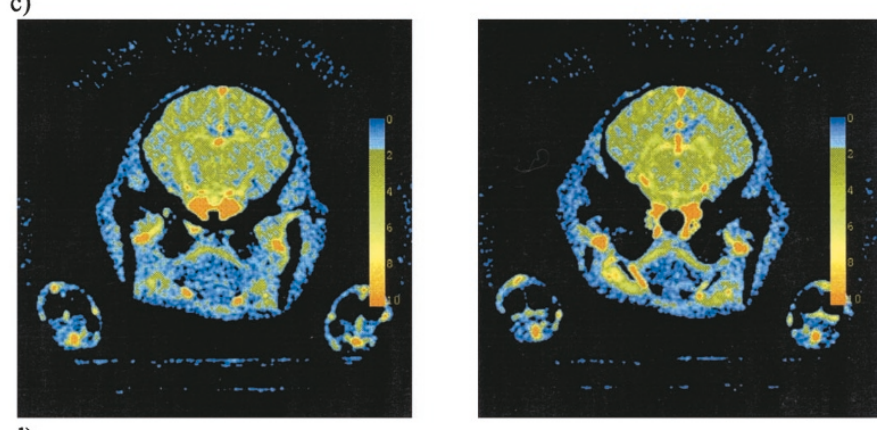

d)
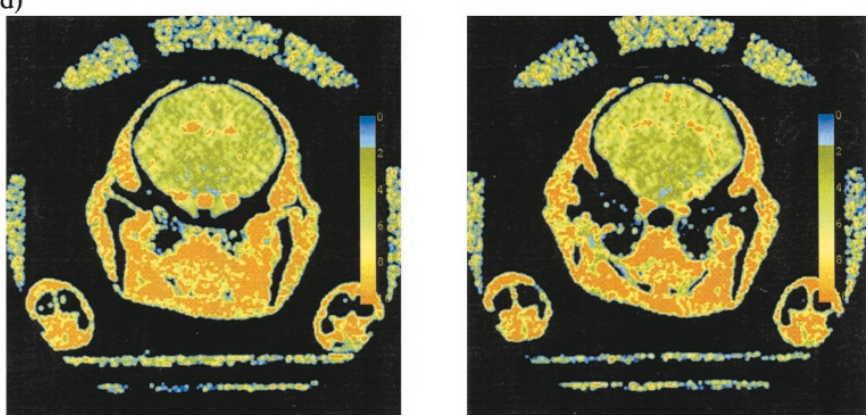

Figure 5. CT images and corresponding $\mathrm{CBF}, \mathrm{CBV}$, and MTT functional maps. (A) Two of a set of four coronal CT images at peak contrast enhancement. The two front legs of the piglet are visible in the bottom corners of the images (black arrows), the brain of the piglet is centered in the image (gray arrow), the lateral ventricles are visible in the mid-brain (transparent arrows), and the arteries are visible as bright spots (white arrows). (B) Corresponding blood flow maps. (C) Corresponding blood volume maps. (D) Corresponding MTT maps. Maps are color coded: $\mathrm{CBF}$ blue $=0 \mathrm{~mL} / \mathrm{min} / 100 \mathrm{~g}$, orange $=100$ $\mathrm{mL} / \mathrm{min} / 100 \mathrm{~g}$; CBV blue $=0 \mathrm{~mL} / 100 \mathrm{~g}$, orange $=10 \mathrm{~mL} / 100 \mathrm{~g}$; MTT blue $=0 \mathrm{~s}$, orange $=10 \mathrm{~s}$. Structures in the CBF and CBV maps that appear orange, flow or volume exceeds $100 \mathrm{~mL} / \mathrm{min} / 100 \mathrm{~g}$ or $10 \mathrm{~mL} / 100 \mathrm{~g}$, respectively, are arterial and venous structures.

\section{DISCUSSION}

The NIRS results correlate well with CT measurements over a range of hemodynamic conditions. Two-way 
Table 2. Physiological parameters for repeated NIRS measurements

\begin{tabular}{|c|c|c|c|c|c|c|}
\hline $\begin{array}{l}\text { Piglet } \\
\text { no. }\end{array}$ & Measurement & $\mathrm{pH}$ & $\begin{array}{c}\mathrm{PaCO}_{2} \\
(\mathrm{~mm} \\
\mathrm{Hg})\end{array}$ & $\begin{array}{c}\mathrm{PaO}_{2} \\
(\mathrm{~mm} \mathrm{Hg})\end{array}$ & $\begin{array}{c}\mathrm{HCO}_{3} \\
(\mathrm{mmol} / \mathrm{L})\end{array}$ & $\begin{array}{c}\text { MAP } \\
(\mathrm{mm} \mathrm{Hg})\end{array}$ \\
\hline 1 & Hypocapnia & 7.587 & 32.1 & 381.3 & 30.7 & 44 \\
\hline \multirow[t]{4}{*}{2} & \multirow[t]{2}{*}{ Hypocapnia } & 7.53 & 30.2 & 396.4 & 25.5 & 55 \\
\hline & & 7.541 & 30.9 & 408.3 & 26.8 & 57 \\
\hline & Normocapnia & 7.45 & 39.3 & 420.3 & 27.3 & 57 \\
\hline & Hypercapnia & 7.322 & 54.5 & 369.5 & 28.9 & 56 \\
\hline \multirow[t]{4}{*}{3} & \multirow[t]{2}{*}{ Hypocapnia } & 7.58 & 29.3 & 358.9 & 27.6 & 50 \\
\hline & & 7.589 & 29.6 & 340.6 & 28.5 & 54 \\
\hline & \multirow[t]{2}{*}{ Normocapnia } & 7.486 & 39.2 & 381.8 & 29.2 & 51 \\
\hline & & 7.466 & 39.5 & 390 & 28.1 & 50 \\
\hline 4 & Hypocapnia & 7.566 & 30.9 & 83.4 & 28 & 53 \\
\hline \multirow{3}{*}{5} & Normocapnia & 7.474 & 37.9 & 234.1 & 27.7 & 56 \\
\hline & \multirow[t]{2}{*}{ Hypercapnia } & 7.357 & 57.5 & 181.6 & 31.5 & 57 \\
\hline & & 7.337 & 56.2 & 174.7 & 29.2 & 57 \\
\hline \multirow[t]{6}{*}{6} & \multirow[t]{2}{*}{ Hypocapnia } & 7.548 & 32.3 & 204.4 & 28.8 & 52 \\
\hline & & 7.555 & 31.4 & 199.9 & 28.4 & 48 \\
\hline & \multirow[t]{2}{*}{ Normocapnia } & 7.459 & 41.4 & 204.8 & 29.8 & 52 \\
\hline & & 7.457 & 42.1 & 208.7 & 30.2 & 50 \\
\hline & \multirow[t]{2}{*}{ Hypercapnia } & 7.342 & 54 & 177 & 28.8 & 51 \\
\hline & & 7.357 & 52.3 & 209.5 & 29 & 50 \\
\hline
\end{tabular}

MAP, mean arterial pressure.

ANOVA showed no significant differences between $\mathrm{CT}$ and NIRS measurements of CBF, CBV, and MTT. The estimated bias, using the Bland-Altman method (22), was small relative to the respective mean values in each case. In some instances, the disagreement between NIRS- and CTmeasured CBF values was quite large. This, coupled with the observation that linear regression fits to the individual NIRS-measured $\mathrm{CBF} \mathrm{PaCO}_{2}$ data were approximately parallel, suggests that the NIRS technique may be better suited for comparison of $\mathrm{CBF}$ values measured from the same piglet rather than for comparisons between piglets. These results show that the NIRS system is capable of accurate, reliable, bedside measurement of cerebral hemodynamics in newborn piglets. There are, however, several factors that should be addressed before clinical trials of the NIRS system can be considered. With respect to skull composition and thickness, the piglet head mimics that of a newborn infant. However, the two are significantly different in terms of size and dimension. In this study, an optode separation of $3.0 \mathrm{~cm}$ was used; this yields a maximum light path penetration depth of $1.73 \mathrm{~cm}$. It has been shown that in newborn infants, the tissues overlying the brain are $<5 \mathrm{~mm}$ thick and do not interfere with NIR monitoring of the brain for emitter-detector separation of at least $3 \mathrm{~cm}$ (23). An increase in optode separation provides increased penetration depth, but it also introduces noise into the detected NIR signal. This would eventually affect the ability of the NIRS system to reliably measure concentration and thus would have a deleterious effect on the precision of NIRS cerebral hemodynamic measurements. In our piglet studies, physical lim- itations prevented use of a greater optode separation. The minimal level of noise present in the concentration data presented here suggests that small increases in optode separation would not greatly affect the overall performance of the system. In addition, the system allows measurement in a single region only, meaning that an investigation of the entire cerebral cortex would require repositioning of optodes. Although repositioning the optodes is not difficult, it does detract from the convenience and ease of use of the system. Addition of further detection optodes around the emission optode would allow sampling of multiple regions, thereby providing measurements across the entire brain (cortex) and eliminating the need to reposition optodes.

A final concern with the NIRS method is that it requires an injection of ICG. Although the use of an exogenous blood flow tracer is somewhat less appealing than using one of the endogenous NIR absorbers (e.g. $\mathrm{HbO}_{2}$ or $\mathrm{Hb}$ ), it is often of less risk to an already unstable patient than changing the arterial oxygen saturation $\left(\mathrm{SaO}_{2}\right)$ of the subject and can be more convenient in the clinical setting. Furthermore, ICG results in much higher signalto-noise ratio data than does manipulation of $\mathrm{SaO}_{2}$. ICG has been used to measure various physiologic parameters such as cerebral blood flow (11), hepatic function (24), plasma volume (25), cardiac output (26), and left-to-right shunts (27) in infants since 1965. One study, involving more than 3000 human subjects, showed that i.v. injection of ICG resulted in significant allergic reaction in only one subject (28).

In current clinical practice, identification of neonates at risk of ischemic injury relies heavily on measurements made using ultrasonography (29). This modality is not able to 


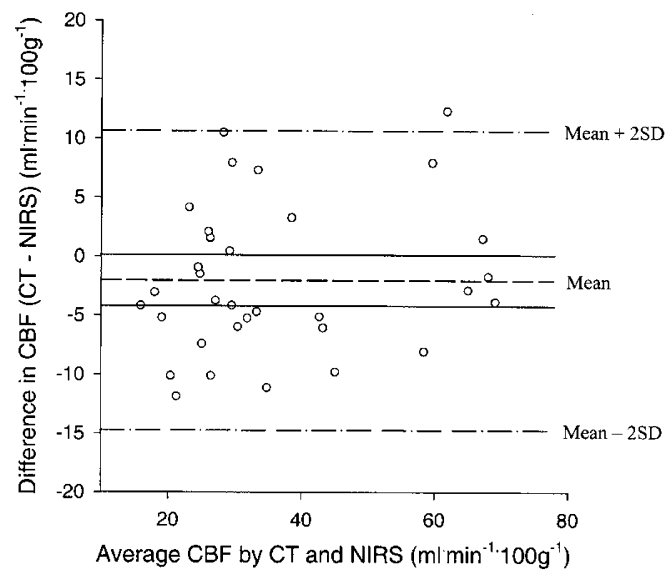

Figure 6. Bland-Altman plot comparing CT and NIRS measurements of $\mathrm{CBF}$. The mean difference between the two methods is $-2.05 \mathrm{~mL} \cdot \mathrm{min}^{-1} \cdot 100$ $\mathrm{g}^{-1}$. The limits of agreement, the region in which $95 \%$ of the differences lie, are -14.73 and $10.64 \mathrm{~mL} \cdot \mathrm{min}^{-1} \cdot 100 \mathrm{~g}^{-1}$. The $95 \%$ confidence interval of the mean difference, the region in which we expect (with $95 \%$ confidence) the bias lies, is -4.21 to $0.12 \mathrm{~mL} \cdot \mathrm{min}^{-1} \cdot 100 \mathrm{~g}^{-1}$. The dashed line shows the mean difference, the dash-dot-dash lines show the limits of agreement, and the solid lines show the $95 \%$ confidence intervals of the mean difference.

provide absolute values for CBF because it measures only blood flow velocities in the vessels studied, generally the middle cerebral arteries. Because the middle cerebral artery carries a large portion of the total blood flow to the brain, it is assumed that its flow is representative of the bulk hemispheric blood flow. Although detection of high velocities can lead to relatively accurate assumptions about the state of global hemispheric blood flow, the method is not able to detect minor, but potentially damaging, changes in CBF, nor is it able to provide any information about the location of possible infarct or injury.

The results presented here clearly demonstrate the ability of the NIRS system to overcome some of the limitations of ultrasonography. It is able to accurately measure cerebral hemodynamics at the bedside and thus would be an invaluable tool for monitoring and diagnosing both hemorrhage and ischemic injury in severely premature infants. In the case of ischemic injury, blood flow is often low for an extended period of time before symptoms of injury are apparent. The ability to detect diminished blood flow at an earlier stage would significantly aid earlier intervention and greatly reduce mortality and morbidity from ischemic injury. It has also been suggested that loss of $\mathrm{PaCO}_{2}$ reactivity is associated with poor neurodevelopmental outcome and/or hypoxic-ischemic encephalopathy and that the loss of $\mathrm{PaCO}_{2}$ reactivity is a candidate for predicting early severe brain damage in preterm infants $(30$, 31 ). Because the NIRS system presented in this study is capable of providing reliable, noninvasive, repeatable measurements, it can be used to detect loss of $\mathrm{PaCO}_{2}$ reactivity, thereby greatly improving diagnosis. The portable nature of the system also provides a distinct advantage over conventional CT/MRI scanners for those patients whose condition renders transport unfavorable.

Acknowledgments. The authors thank animal health technician Jennifer Hadway for her help in the experiments.

\section{REFERENCES}

1. Jobsis FF 1977 Non-invasive infrared monitoring of cerebral and myocardial oxygen sufficiency and circulatory parameters. Science 198:1264-1267

2. Brazy JE, Lewis DV 1986 Changes in cerebral blood volume and cytochrome aa3 during hypertensive peaks in preterm infants. Pediatrics 108:983-987

3. Ferrari M, De Marchis C, Giánnini I, DiNicola A, Agostino R, Nodari S, Bucci G 1986 Cerebral blood volume and haemoglobin oxygen saturation monitoring in neonatal brain by near infrared spectroscopy. Adv Exp Med Biol 200:203-211

4. Chance B, Legallais V, Sorge J, Graham N 1975 A versatile time-sharing multichannel spectrophotometer, reflectometer, and fluorometer. Anal Biochem 66:498-514

5. Wyatt JS, Cope M, Delpy DT, Wray S, Reynolds EO 1986 Quantification of cerebral oxygenation and haemodynamics in sick newborn infants by near infrared spectrophotometry. Lancet 2:1063-1066

6. Cope M, Delpy DT 1988 System for long-term measurement of cerebral blood and tissue oxygenation on newborn infants by near infra-red transillumination. Med Biol Eng Comput 26:289-294

7. Yoxall CW, Weindling AM, Dawani NH, Peart I 1995 Measurement of cerebral venous oxyhemoglobin saturation in children by near-infrared spectroscopy and partial jugular venous occlusion. Pediatr Res 38:319-323

8. Reynolds EO, Wyatt JS, Azzopardi D, Delpy DT, Cady EB, Cope M, Wray S 1998 New non-invasive methods for assessing brain oxygenation and haemodynamics. $\mathrm{Br}$ Med Bull 44:1052-1075

9. Delpy DT, Cope M, van der Zee P, Arridge S, Wray S, Wyatt JS 1988 Estimation of optical pathlength through tissue from direct time of flight measurement. Phys Med Biol 33:1433-1442

10. Elwell CE, Cope M, Edwards AD, Wyatt JS, Delpy DT, Reynolds EO 1994 Quantification of adult cerebral hemodynamics by near-infrared spectroscopy. J Appl Physiol 77:2753-2760

11. Patel J, Marks K, Roberts I, Azzopardi D, Edwards AD 1998 Measurement of cerebral blood flow in newborn infants using near infrared spectroscopy with indocyanine green. Pediatr Res 43:34-39

12. Matcher SJ, Cope M, Delpy DT 1994 Use of the water absorption spectrum to quantify tissue chromophore concentration changes in near-infrared spectroscopy. Phys Med Biol 39:177-196

13. Cenic A, Nabavi DG, Craen RA, Gelb AW, Lee TY 1999 Dynamic CT measurement of cerebral blood flow: a validation study. AJNR Am J Neuroradiol 20:63-73

14. van Bel F, van de Bor M, Baan J, Ruys JH 1988 The influence of abnormal blood gases on cerebral blood flow velocity in the preterm newborn. Neuropediatrics 19:27-32

15. Madden JA 1993 The effect of carbon dioxide on cerebral arteries. Pharmacol Ther 59:229-250

16. Bonner RF, Nossal R, Havlin S, Weiss GH 1987 Model for photon migration in turbid biological media. J Opt Soc Am A Opt Image Sci Vis 4:423-432

17. Bassingthwaigthe JB, Chinard FP, Crone C, Lassen NA, Perl W 1970 Definitions and terminology for indicator dilution methods. In: Crone C, Lassen NA (eds) Capillary Permeability. Munskgaard, Copenhagen, pp 665-669

18. Zierler KL 1965 Equations for measuring blood flow by external monitoring of radioisotopes. Circ Res 16:309-321

19. Meier PP, Zierler KL 1954 On the theory of the indicator-dilution method for measurement of blood flow and volume. J Appl Physiol 6:731-744

20. Snedecor GW, Cochran WG 1967 Statistical Methods. The Iowa State University Press, Ames, IA, pp 472-477

21. Lawson CE, Hanson RJ 1974 Solving Least Squares Problems. Prentice-Hall, Englewood Cliffs, NJ, pp 159-173

22. Bland JM, Altman DG 1986 Statistical methods for assessing agreement between two methods of clinical measurement. Lancet 1:307-310

23. Benaron DA, Kurth CD, Steven JM, Delivoria-Papadopoulos M, Chance B 1995 Transcranial optical path length in infants by near-infrared phase-shift spectroscopy. J Clin Monit Comput 11:109-117

24. Evans WE, Relling MV, de Graaf S, Rodman JH, Pieper JA, Christensen ML, Crom WR 1989 Hepatic drug clearance in children: studies with indocyanine green as a model substrate. J Pharm Sci 78:452-456

25. Anthony MY, Goodall SR, Papouli M, Levene MI 1992 Measurement of plasma volume in neonates. Arch Dis Child 67:36-40

26. O'Connell AJ, Tibballs J, Coulthard M 1991 Improving agreement between thoracic bioimpedance and dye dilution cardiac output estimation in children. Anaesth Intensive Care 19:434-440

27. Krovetz LJ, Gessner IH 1965 A new method utilizing indicator-dilution technics for estimation of left-to-right shunts in infants. Circulation 32:772-777

28. Hope-Ross M, Yannuzzi LA, Gragoudas ES, Guyer DR, Slakter JS, Sorenson JA, Krupsky S, Orlock DA, Puliafito CA 1994 Adverse reactions due to indocyanine green. Ophthalmology 101:529-533

29. Blankenberg FG, Loh NN, Bracci P, D'Arceuil HE, Rhine WD, Norbash AM, Lane B, Berg A, Person B, Coutant M, Enzmann DR 2000 Sonography, CT, and MR imaging: a prospective comparison of neonates with suspected intracranial ischemia and hemorrhage. AJNR Am J Neuroradiol 21:213-218

30. Blankenberg FG, Loh NN, Norbash AM, Craychee JA, Spielman DM, Person BL, Berg CA, Enzmann DR 1997 Impaired cerebrovascular autoregulation after hypoxicischemic injury in extremely low-birth-weight neonates: detection with power and pulsed wave Doppler US. Radiology 205:563-568

31. Muller AM, Morales C, Briner J, Baenziger O, Duc G, Bucher HU 1997 Loss of $\mathrm{CO}_{2}$ reactivity of cerebral blood flow is associated with severe brain damage in mechanically ventilated very low birth weight infants. Europ J Paediatr Neurol 1:157-163 